\title{
A Self-Directed Mobile Intervention (WaznApp) to Promote Weight Control Among Employees at a Lebanese University: Protocol for a Feasibility Pilot Randomized Controlled Trial
}

\author{
Marco Bardus $^{1^{*}}, \mathrm{PhD}$; Ghassan Hamadeh ${ }^{2 *}, \mathrm{MD}$; Bouchra Hayek ${ }^{1 *}, \mathrm{MPH}$; Rawan Al Kherfan ${ }^{1 *}$, BSc \\ ${ }^{1}$ Department of Health Promotion and Community Health, Faculty of Health Sciences, American University of Beirut, Beirut, Lebanon \\ ${ }^{2}$ Department of Family Medicine, Faculty of Medicine, American University of Beirut, Beirut, Lebanon \\ *all authors contributed equally
}

Corresponding Author:

Marco Bardus, PhD

Department of Health Promotion and Community Health

Faculty of Health Sciences

American University of Beirut

Van Dyck - Room 302

PO Box 11-0236 Riad El Solh

Beirut, 11072020

Lebanon

Phone: 9611350000 ext 4694

Fax: 9611744470

Email: marco.bardus@gmail.com

\begin{abstract}
Background: Overweight and obesity have become major health problems globally with more than 1.9 billion overweight adults. In Lebanon, the prevalence of obesity and overweight is $65.4 \%$ combined. Risk factors of obesity and overweight are preventable and can be addressed by modifications in the environment and in an individual's lifestyle. Mobile technologies are increasingly used in behavioral, self-directed weight management interventions, providing users with additional opportunities to attain weight control (weight loss, weight gain prevention, etc). Mobile apps may allow for the delivery of Just-in-Time Adaptive Interventions (JITAIs), which provide support through skill building, emotional support, and instrumental support, following the participants' progress. A few commercially available apps offer JITAI features, but no studies have tested their efficacy.

Objective: The primary objective of this study is to examine the feasibility of a self-directed weight loss intervention, targeting employees of an academic institution, using a virtual coaching app with JITAI features (Lark) and a self-help calorie-counting app (MyFitnessPal). The secondary objective is to estimate the effects of the intervention on main study outcomes.

Methods: This study is a single-center, parallel, randomized controlled trial with 2 study arms (intervention and control). Participants will be randomly allocated in equal proportions to the intervention (Lark) and control groups (MyFitnessPal). To be eligible for this study, participants must be employed full- or part-time at the university or its medical center, able to read English, have a smartphone, and be interested in controlling their weight. Recruitment strategies entail email invitations, printed posters, and social media postings. We will assess quantitative rates of recruitment, adherence, and retention, self-reported app quality using the user version of the Mobile App Rating Scale. We will also assess changes in weight-related outcomes (absolute weight and waist circumference), behavioral outcomes (physical activity and diet), and cognitive factors (motivation to participate in the trial and to manage weight).
\end{abstract}

Results: WaznApp was funded in June 2017, and recruitment started in March 2018.

Conclusions: This study will provide information as to whether the selected mobile apps offer a feasible solution for promoting weight management in an academic workplace. The results will inform a larger trial whose results might be replicated in similar workplaces in Lebanon and the Middle East and North Africa region, and will be used as a benchmark for further investigations in other settings and similar target groups.

Trial Registration: ClinicalTrials.gov NCT03321331; https://clinicaltrials.gov/ct2/show/NCT03321331 (Archived by WebCite at http://www.webcitation.org/6ys9NOLo5) 
Registered Report Identifier: RR1-10.2196/9793

(JMIR Res Protoc 2018;7(5):e133) doi: 10.2196/resprot.9793 KEYWORDS

mobile apps; weight loss; physical activity; healthy diet; workplace; mHealth; randomized controlled trial

\section{Introduction}

\section{Background}

Noncommunicable diseases (NCDs), also known as chronic diseases, are one of the major global public health challenges of the 21 st century, being responsible for about 40 million deaths per year, 15 of which are premature (ie, between 30 and 69 years) [1]. The majority of these deaths occur in low- and middle-income countries (LMICs). According to the World Health Organization's (WHO's) global report, cardiovascular diseases, cancer, diabetes, and chronic respiratory diseases are responsible for $82 \%$ of all NCD deaths [2]. In Lebanon, the prevalence of NCDs accounts for $85 \%$ of all deaths. NCDs are the product of 4 main risk factors: tobacco use, physical inactivity, the harmful use of alcohol, and unhealthy diets, which, in turn, lead to 4 key metabolic changes (raised blood pressure, overweight and obesity, raised blood glucose, and raised cholesterol) [1]. With regard to overweight and obesity, globally, in 2014, there were more than 1.9 billion overweight adults, representing $39 \%$ of the world population. Of these, 600 million were obese [3]. In Lebanon, the prevalence of obesity and overweight is $65.4 \%$ (obesity accounting for $27.4 \%$ and overweight for $38 \%$ ) [4]. A fundamental cause of obesity and overweight is an energy imbalance between caloric intake and caloric consumption. This imbalance is due to global trends of increased availability and intake of energy-dense foods that are high in sugar and saturated fats, and insufficient physical activity, due to the sedentary nature of many forms of work, modes of transportation, and increased urbanization [3]. All these behavioral risk factors are preventable, as they can be addressed by modifications in the environment and lifestyle of individuals (ie, increasing physical activity, reducing sedentary time, and following a healthy diet) [5].

The effectiveness of nonsurgical and behavioral weight management interventions has been demonstrated in several systematic reviews and meta-analyses [6,7]. For example, commercially available weight loss treatments, such as WeightWatchers, and pharmaceutical products, such as Qsymia, were found to be cost-effective strategies to achieve weight loss [8]. Effective behavioral interventions should include both physical activity and dietary components to reach larger and sustained effects [9]. Self-monitoring is one of the most effective change techniques [10] included in behavioral weight loss interventions, as evidence shows that people who report weight monitoring on a daily or weekly basis tend to be more successful in attaining weight loss goals $[11,12]$. Self-monitoring improves the awareness of caloric and food intake, increases self-efficacy, and permits the evaluation of any change or progress over time [13]. However, long-term weight loss and maintenance interventions that are delivered face-to-face usually require substantial work of a specialist workforce and sizeable resources, both from the participants and the service providers.

In the past decade, "health services and information delivered or enhanced through the internet and related technologies" (ie, "eHealth") [14] have transformed the way patients interact with the health care system [15] and engage with their own health [16]. eHealth technologies allow users to monitor, track, and inform their health; communicate between health agencies and external stakeholders in terms of health; and collect, manage, and use health data [17]. In this context, new strategies for behavioral weight management interventions have been developed [18-22], with the aim to provide users with the support necessary to attain weight loss and, at the same time, contain costs [23]. The potential of eHealth and mobile health (mHealth) is especially relevant to LMICs, where phone ownership is rising rapidly, but access to health care services is often limited. Recent systematic reviews on eHealth behavioral interventions addressing NCDs and their risk factors in LMICs show promising results $[24,25]$. The attention toward mHealth apps is also justified by the high penetration rates of these technologies. According to a 2014 Pew Research Center survey, in Lebanon, the penetration rate of mobile phones was $86 \%$, with smartphones reaching $45 \%$, the highest penetration rate in the Middle East and North Africa (MENA) region [26]. Smartphone ownership is as high as $60 \%$ among adults aged 18 to 29 years and 55\% among adults aged 30 to 49 years [26]. More recent data (October 2016 to November 2017) available from Net Marketshare show that mobile and tablet represent $61 \%$ of the market in Lebanon, with Android capturing 61\% and $\mathrm{iOS}$ capturing $38 \%$ of the Lebanese market.

Mobile phones, and particularly apps, have been considered convenient intervention platforms as they are portable, appealing, and universal [27]. Mobile phones can be used for self-directed interventions for weight management. Self-directed interventions are those that "require minimal professional contact (eg, provision of initial instructions) or no professional contact and can be easily used with existing infrastructure and in the context of users' everyday lives" [28]. Mobile apps started to show some suggestive evidence of effectiveness [18,29], with studies reporting positive effects in weight reduction when apps were employed as a supplement to telephone coaching [30]. However, small, nonsignificant effects were reported when apps were used as a standalone tool [31,32]. Smartphones are the ideal platform for delivering self-directed, Just-in-Time Adaptive Interventions (JITAIs), which are treatment programs that, as the name suggests, adapt to the patients' progress, eg, when they attain goals or positively respond to treatment [33]. JITAIs can provide support through skill building (coping, making decisions, planning, etc), emotional support (encouragement, etc), and instrumental support (feedback, etc) when users need these features the most [33,34]. JITAIs are complex, 
algorithm-dependent interventions based on several design principles, which include decision points and outcomes that would inform the provision of tailored feedback (ie, tailoring variables), intervention options (based on if-then conditions grounded on behavioral theories, aimed at addressing short-term behavioral outcomes), and decision rules. For a more detailed overview of the JITAI framework, we refer the reader to the seminar report by Nahum-Shani et al [34]. Mobile devices are adequate platforms for delivering feasible and scalable JITAIs, given the smartphone technology advancements that are providing users with continuous monitoring and personalized coping strategies [34]. Nevertheless, little is known about the efficacy of mobile apps acting as main components of JITAIs for weight management.

According to the WHO's global action plan for the prevention and control of NCDs [35], workplaces are one of the most important settings for health promotion as they are the gateway to a large number of people (about $65 \%$ of the world's population is employed) [36]. In the last two decades, many public health efforts have been made, and numerous interventions have been conducted to tackle these problems. There is a wide evidence supporting the effectiveness of workplace interventions for the prevention of obesity [37-40], and many national governments adopted policy decisions for promoting health through workplaces. In response to the WHO call for action, the Lebanese Ministry of Public Health released a plan for the prevention and control of NCDs in 2016 [4], which provides a set of guidelines for action, despite excluding workplaces as a setting for priority interventions. This gap is being filled by the American University of Beirut (AUB) and its Medical Center (AUBMC) [41], which have expressed their commitment toward building a healthier campus and community through a long-term strategic plan endorsed in the Health 2025 vision.

\section{Aims of This Study}

The overarching goal of this study is to determine the feasibility and preliminary efficacy of a self-directed weight management intervention, targeting university employees and delivered entirely through mobile apps. Specifically, the study aims to (1) evaluate the acceptability and feasibility of using 2 commercially available mHealth apps for weight management; (2) evaluate the feasibility of implementation strategies, retention, and adherence to the study, fidelity to the protocol, assessments, and data collection procedures; and (3) estimate the effects of the interventions on weight-related outcomes (eg, weight, body mass index, and waist circumference), as well as on behavioral (physical activity and diet), and cognitive factors related to weight loss (motivation to lose weight, to engage in physical activity, and follow a healthy diet).

\section{Methods}

\section{Participants and Procedures}

Participants are employees working at AUB and its Medical Center (AUBMC), located in Beirut, Lebanon. Employees include faculty $(n=1182)$, of which $41.03 \%(485 / 1182)$ are female; nonacademic staff at AUB $(n=1266)$ of which $46.99 \%$ $(595 / 1266)$ are female; and AUBMC staff $(n=3038)$ of which
$52.00 \%(1580 / 3038)$ are female [41]. The employer did not influence the design of the study or its methodology. The recruitment strategy does not rely on the endorsement of any AUB or AUBMC authorities. Participants will be informed orally and through written consent forms that their participation is completely voluntary, free of charge, and no penalty will be pressed for those not willing to participate.

To be enrolled in the study, participants must (1) be employed full- or part-time; (2) be able to read, write, and understand English; (3) own a smartphone with either Android (v4.4 or above) or iOS (v8 or later); and (4) be interested in better controlling their weight (ie, losing weight, preventing weight gain, maintaining weight lost, or gaining weight in a healthy way). Exclusion criteria include the following: (1) being full-time students who cannot prove their status as full- or part-time employees at AUB or AUBMC; (2) not being able to read, write, and understand English; (3) not owning a smartphone with either Android (v4.4 or above) or iOS (v8 or later); (4) having physical disabilities preventing from exercising or walking; (5) being on a special diet for treatment of chronic conditions (eg, diabetes); (6) being diagnosed with anorexia or bulimia nervosa; (7) being on weight loss medications; and (8) having undergone bariatric surgery in the past 3 months. The trial is registered at ClinicalTrials.gov [NCT03321331]. The protocol of this study has been approved by the local Institutional Review Board (ref \#FHS.MB.07/SBS-2017-0416).

\section{Recruitment and Randomization}

Participants will be recruited through email invitations sent from the AUB Health and Wellness Center, and printed posters hanged on billboards on campus. A digital version of the poster with a shortened link (bit.ly/WaznApp) and QR-code linking to an eligibility screener survey will be displayed on monitors on campus TV screens. Invitations to enroll will also be circulated on social media using the research team's personal and professional social networks (Facebook, Twitter, LinkedIn, and ResearchGate). Emails, posters, and social media postings will contain a link leading to an eligibility screener survey, which will first display an informed consent form. The survey, designed using LimeSurvey, is hosted on AUB servers. At the end of the form, employees will be instructed to complete their enrolment by visiting the University Health Services (UHS) clinics, where nurses will verify their eligibility and take basic anthropometric measurements (ie, height, weight, and waist circumference). Nurses will fill out paper-based forms, thereby cross-checking their eligibility to participate in the study. If participants are eligible, nurses will inform the participants that the research team will contact them via email with information about the next steps in the study. Nurses will provide a hard copy of the consent form to all participants.

Randomization procedures will take place after employees are confirmed to be enrolled in the study. A random sequence based on the minimization procedure will be generated using a computer program, following Altman and Bland's approach [42]. The minimization procedure allows to balance the allocation of study participants to a prespecified number of treatment groups as soon as they enroll in the study, considering participant characteristics (ie, stratification by gender, age, and 
anthropometric features) collected during the eligibility phase. The program used to perform the minimization procedure is QMinim [43]. A statistician from the Faculty of Health Sciences will generate the sequence using the program. The random sequence will be uploaded to the REDCap (Research Electronic Data Capture) platform [44]. The research team will inform participants about their allocation after the visit, with a welcome email.

As we need to provide intervention participants with a link to download a full version of the app, allocation concealment and blinding cannot be applied. However, efforts will be implemented to reduce allocation bias. First, the clinical staff weighing participants at baseline and Week 12 will be blinded to treatment groups. Second, after the baseline clinic visit and the initial account set-up, minimization procedures will be undertaken by a statistician, not involving the principal investigator. Third, the intervention is completely delivered via mobile apps. The only contact is related to study procedures and data collection. Finally, data analysis will be conducted on masked data.

\section{WaznApp Study Overview}

The WaznApp study is part of a larger project entitled "Can commercial mobile apps for weight management be used in interventions? Bridging the gap between usability, theoretical adherence, and user experience." The project included a formative phase, which was based on a user-centered heuristic evaluation study, aimed at understanding how members of the employee community perceive 6 weight management apps (Lark, MyFitnessPal, SparkPeople, MyPlate, My Diet Diary, and My Diet Coach). The 6 apps were selected because they achieved the highest total scores on the Mobile App Rating Scale (MARS) [45], in a recent expert review [46]. In the heuristic evaluation study, 36 employees were randomly assigned to use one of these apps for 2 weeks. At the end of this period, they submitted their app quality evaluation using the user version of the MARS scale (uMARS) [47]. Three apps achieved the highest mean ratings for the total app quality score (Lark=4.0; MyPlate=3.8; MyFitnessPal=3.7). Lark clearly emerged as the app with the highest quality scores. In addition, this app has been recently employed in an observational study, involving 70 diabetic patients, who lost $2.4 \%$ of their weight at baseline after about 15 weeks [48]. Users of MyPlate reported several functionality issues, and its database is not as complete and responsive as its popular counterpart MyFitnessPal, which is one of the most downloaded apps for dietary tracking [49]. Compared with another popular app (Lose It!), MyFitnessPal allows users to automatically track activity through the phone or through integrations with many wearable devices [50]. For these reasons, we selected Lark and MyFitnessPal as trial apps.

The WaznApp study is a 12-week, prospective, single-center, parallel, randomized controlled trial with 2 study arms. The intervention arm will use Lark, a mobile coach, which provides interactive counseling through a chat-style interface by delivering motivational feedback, goal setting, and emotional social support. Lark acts as an adaptive intervention [33] and provides feedback on several outcomes (see, eg, the text and app-based Cell Phone Intervention for You trial [51,52]). The content of the messages depends on the way users interact with the app. The content is based on several behavior change techniques, such as goal setting, reviewing behavioral goals, feedback, and social support [46]. The users input their activities, foods or weight, but the app tracks automatically their active time using proprietary algorithms and phone motion sensors. The control group will use MyFitnessPal, a calorie-counting app that does not include JITAI components and relies on the user input for food tracking. MyFitnessPal acts as the control condition, as it provides limited social support, which is present in Lark, and it is an important feature that is generally lacking in calorie-counting apps [53].

\section{Description of Treatment Arms}

\section{Intervention Arm (Just-in-Time Adaptive Intervention)}

Participants in the intervention arm will use Lark Pro for 12 weeks. Lark, developed by Lark Technologies Ltd, is a personal weight management health coach based on artificial intelligence that interacts with the user in a chat-like format. Lark Pro includes a personalized health plan and nutrition coaching, as well as physical activity, weight, sleep, and mood tracking. Once the app is launched, Lark checks the data that the user inputted (ie, food meals; physical activities such as walks, runs, bike, and workouts; and weight) or that was automatically logged through the phone motion sensors (ie, activity, sleep) or external devices (eg, Apple Watch, digital scales). On the basis of this information, Lark generates interactive conversations every time individuals use the app. Conversations about meal logging are geared toward food choices and portions rather than calorie counting; conversations may include messages that provide solutions to problematic situations, fostering action planning and problem-solving skills. The app sends notifications to prompt the users to review their activity throughout the day. Following the behavior change technique taxonomy v1 [10], Lark includes the following techniques: "goal setting" of behavior and outcomes (eg, activity, weight), "review outcome goals," "self-monitoring" of behavior and outcomes, and "feedback" on behavior or on outcomes of behavior (Figure 1). In addition, users may receive "information about health consequences" (eg, when inputting a "muffin" as a meal, the app may respond: "That wasn't the healthiest of meals/When I say this I am referring to the quality of the actual foods rather than taking into account the quantity you eat, but obviously eating an entire dessert is less healthy than having a single taste"). Lark also helps users to develop "problem-solving" skills (Figure 2), providing alternative solutions ("What's a healthier choice?" response: "You could try fruit, which is sweet, filling, and packed with antioxidants"). The app also provides "emotional support" (eg, "know that when it comes to weight loss, ups and downs are typical") and "positive reinforcement" (Figure 3). Sometimes, the app suggests information based on "credible sources," as it has been developed in collaboration with researchers from Stanford and Harvard universities.

In agreement with Lark Technologies, users will utilize an app that will not be updated until the end of the study, to minimize variability in the intervention delivery. 
Figure 1. Example of self-monitoring of physical activity and visual feedback on behavior.

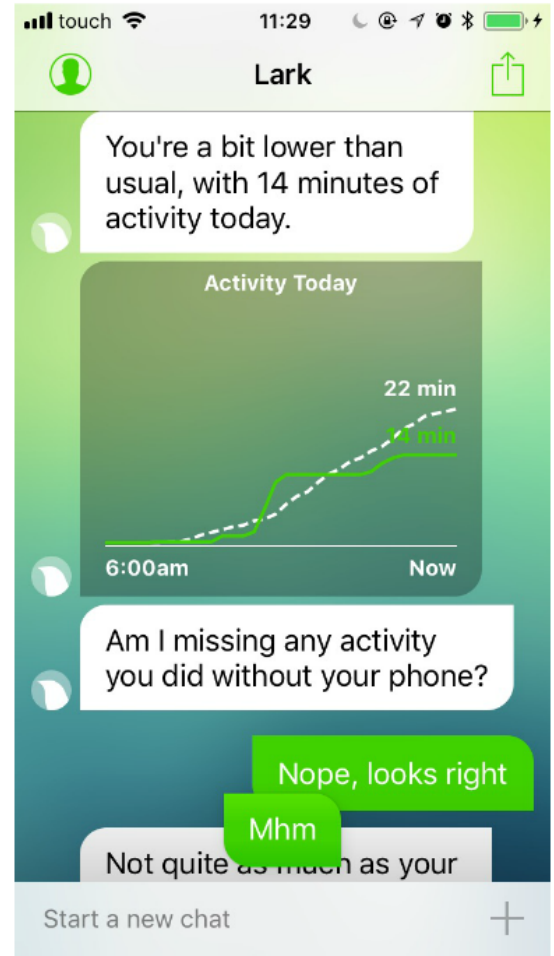

Figure 2. Example of mindful logging with problem-solving skills.

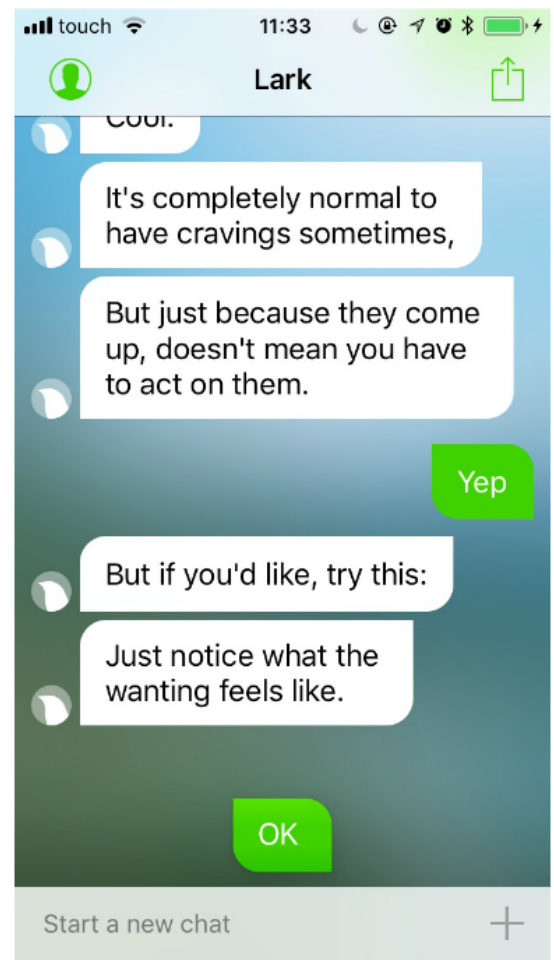


Figure 3. Example of positive reinforcement (ie, "social reward").

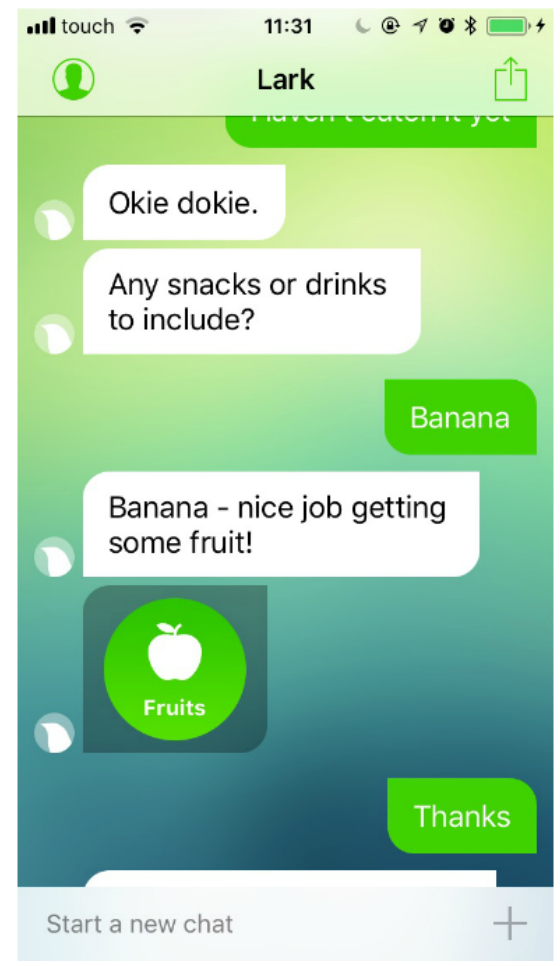

\section{Control Arm (No Just-in-Time Adaptive Intervention)}

Participants in the control arm will be assigned to use MyFitnessPal. Similar to participants in the JITAI arm, they will be instructed to use the app for 12 weeks. MyFitnessPal does not include JITAI components, but it allows users to keep track of their caloric intake and energy expenditure. According to the previously cited review of mHealth apps for weight management [46], MyFitnessPal also has features that can be associated with effective behavior change techniques, including self-monitoring of behavior and outcomes, goal setting, and feedback (similar to Lark). In MyFitnessPal, social support is limited to comments and "likes" from friends of its restricted user community; hence, it might include "social comparisons" and "social reward" behavior change techniques [10]. MyFitnessPal acts as an active control arm as it relies almost exclusively on self-control, compared with Lark, as the latter provides an emotional social support from the coach, who provides positive enforcement and motivational messages to further encourage behavior change.

\section{Additional Components}

This study will be delivered almost entirely through mobile phones. Face-to-face interactions with the research team will be kept at minimum and used only to ensure that the mobile apps have been installed correctly, and there are no issues related to the use of technology during the intervention period. Participants will be instructed via manuals and tutorials delivered via email on how to download and use the apps, complete the surveys, and how to use the food composition tables for use in the Middle East [54], available from the local library. Manuals for completing dietary assessment using the Web-based Automated Self-Administered 24-hour (ASA24) Dietary Assessment Tool, version 2016, are available directly on the tool's website. Emails will be used to communicate with study participants and to send them links for completing Web-based intermediate and follow-up assessments (collected through REDCap). The research team will encourage participants to keep their phone with them to track steps and active time, as the phones automatically collect the number of steps walked using built-in accelerometers.

\section{Incentives for Participation}

Study participants will not receive any payment for their participation, but they will be awarded "WaznApp karma points" (WAKpts) for completing tasks related to the study. Karma points are a nonmonetary measure of contribution to the study [55] and are awarded when participants in both intervention groups duly fill the Web-based questionnaires and food records. Each question filled in is worth 1 WAKpt. The points are according to the number of tasks completed. If the participants collect at least 600 points, they will enter the final lottery for Fitbit products, which will take place at the end of the study.

\section{Intervention Administration and Fidelity}

The intervention is delivered by the apps in an automated way. Neither the research team nor the developers have direct contact with participants and will not prompt app use. The research team will send emails to participants only to remind them about data collection procedures via REDCap. All research assistants have undertaken Collaborative Institutional Training Initiative training and acquired certification. Nurses collecting data and eligibility information will be trained before the start of the study. The research team will meet the nurses and provide instructions on how to fill the eligibility forms. Intervention fidelity will be monitored weekly, through meetings with research assistants and through the support of a project management platform (Basecamp), which keeps track of activities and tasks. Participants' compliance with the 
intervention will be assessed through the email data collection points at baseline and Weeks 4, 8, and 12 .

\section{Outcomes}

In this study, primary outcomes are those related to the feasibility, whereas secondary outcomes are those related to the preliminary efficacy. The timeline for data collection is specified for each outcome below. We will collect data mostly through mobile-friendly, Web-based surveys. Participants will be invited to fill the questionnaires via email, which will contain personalized links to the surveys. Before the start of the study, all instruments will be pilot tested.

\section{Feasibility and Acceptability Outcomes}

As done in other similar trial [56], feasibility measures include quantitative rates of recruitment, adherence, and retention. Adherence to the study will be based on the number of data collection points completed and on qualitative feedback related to the study requirements. For Lark users (intervention group), we will use the logs of the app about quality (ie, detail and accuracy) and quantity of meals logged, daily activities logged, weight, sleep duration, and the number of conversations with the Lark coach as measures of intervention adherence. Retention rates will be calculated at the end of the study based on the number of participants who successfully complete the study, excluding dropouts. For both intervention and control groups, we will ask participants to provide information about their weekly app usage (hours/week). In Week 4, 8, and 12 surveys, we will add instructions on how to find the information on iPhones, using the built-in battery saving analytics, or Android phones, using the free app called Frequency: App Usage Tracking.

Acceptability of the trial will be assessed using qualitative feedback collected at each data point through open-ended questions (ie, "What are your major concerns about the study procedures, if you have any?"; "What are your major concerns about the app you have used?"; "What are your major concerns about the questionnaires?" Please elaborate your answers in the box below). Satisfaction with the program will be assessed through a 7-point rating scale (semantic differential), ranging from extremely satisfied to extremely dissatisfied. An open-ended question will give participants the option to elaborate on their response. These measures are calculated at the end of the study (Week 12). Satisfaction with the app will be assessed through the uMARS [47]. The uMARS scale provides a measure of app quality based on the average of 4 subdomains: engagement, functionality, aesthetics, and information; it also includes the subjective quality domain. Each of the subdomains is based on the average value of multiple items, assessed through 5-point Likert scales (engagement: 5 items; functionality and information: 4 items; aesthetics: 3 items; and subjective quality: 4 items). In the uMARS developmental study [47], the total scale and subscales achieved good and excellent internal consistency: engagement (Cronbach alpha=.80); functionality (alpha=.70); aesthetics (alpha=.71); information (alpha=.78), total (alpha=.90), and subjective quality (alpha=.78). As the uMARS tool requires that users utilize the app before rating it, app quality will be collected at Weeks 4, 8 , and 12 (to allow for test-retest reliability estimates).

\section{Secondary Outcomes}

Secondary outcome measures include changes in weight-related outcomes (absolute weight and waist circumference), behavioral outcomes (physical activity and diet), and cognitive factors (motivation to participate in a weight management program). Absolute weight and waist circumference will be measured with standard instruments and procedures at baseline and Week 12 by assessors blinded to arm allocation from AUBMC UHS. Intermediate self-reported measures of weight will be based on weekly check-ins, automatically prompted by the mobile apps, and collected through Web-based forms at Weeks 4 and 8.

Activity information will be captured through the phones, which will be integrated with Google Health Kit, Apple Health, or Samsung S Health. Participants will be asked to read and report average weekly measures of steps walked and weekly active time at Weeks 4, 8, and 12. Lark automatically tracks the amount of active time per day, whereas MyFitnessPal can estimate the number of steps walked using the phone accelerometer or external, third-party devices such as Fitbit, Misfit, and Apple Watch. As not everyone may have their phone with them all the time, we will assess physical activity also through the International Physical Activity Questionnaire, short form (IPAQ-S) [57]. IPAQ-S is one of the most widely adopted self-reported instruments to assess physical activity, which has been designed to be easily used in many languages and countries [58]. Despite the limitations of self-reported instruments compared with objective methods for measuring physical activity (eg, the "gold standard" doubly labeled water), the IPAQ-S is a feasible, easy-to-use instrument to capture physical activity [58]. As there was no budget for more reliable physical activity assessment instruments (eg, Actigraph accelerometers or pedometers), we chose the IPAQ-S because of its ease of use, as it is perceived as less daunting than the long form showing similar reliability and validity estimates [59]. Furthermore, the IPAQ-S tool has been previously used in epidemiological studies in Lebanon [60,61]. The IPAQ-S requires respondents to estimate how much time they spent while doing activities in the previous week in 4 domains: vigorous physical activity, moderate physical activity, walking, and sitting. A total physical activity score is calculated by summing the time spent in each domain. The total physical activity score and subdomain scores can be expressed in hours/week, or converted to metabolic equivalents (METs), following the IPAQ scoring protocol [62]. MET values were derived from the IPAQ Reliability Study [59], and an average MET score will be derived for each type of activity using the compendium of Ainsworth et al [63]: 1 MET equals the energy expenditure of sitting down quietly, $3.5 \mathrm{ml} \mathrm{O}_{2} / \mathrm{kg} / \mathrm{min}$. Physical activity will be assessed through the IPAQ-S questionnaire at baseline and Week 12.

Dietary intake data will be collected and analyzed using the Automated Self-Administered 24-hour (ASA24) Dietary Assessment Tool, version 2016, developed by the National Cancer Institute, Bethesda, MD. ASA24-2016 is based on the Automated Multiple-Pass Method, developed by the United States Department of Agriculture [64]. The multiple-pass approach in 24-hour recall provides a detailed assessment of dietary intake over the past 24 hours, including food, drinks, 
and supplements, as well as timing, form, portion size, the way food has been prepared, and the consumption of additions such as sugar, cream, and dressing, in addition to the source/brand of food. The 2016 version of the system includes also pictures of portions that are deemed to reduce overestimation or underestimation of food intake [65]. Since its release date (April 2016), ASA24-2016 has been used in 882 studies and 37,090 recalls have been completed. Various versions of ASA24 have also been used in self-directed weight loss interventions [66-68]. The automated version of ASA24 generally showed good reliability compared with the interviewer-administered version [69] or with the measures of true intake [70]. The ASA24-2011 version has been validated against and shown close agreement with interview-administered 24-hour dietary recalls among adults and children [70,71]. In this study, participants will complete an ASA24 at baseline and at the end of the intervention. The ASA24-2016 will be used on 3 nonconsecutive days ( 2 in a week day and 1 in a weekend, eg, Mondays, Thursdays, and Saturdays). Participants will access the Web-based ASA24 platform where they will be asked to recall food, drinks, or supplements they consumed in the last 24 hours. The questionnaire can be accessed via mobile phones, as it uses a responsive Web interface. Energy and macronutrients estimates will be computed using the Nutritionist Pro Software, using the United States Department of Agriculture (USDA) database (version 5.1.0, 2014, First Data Bank, Nutritionist Pro, Axxya Systems, San Bruno, CA). For composite dishes or items that are not included in the USDA database, traditional recipes will be added to the Nutritionist Pro Software, using single food items. ASA24-2016 will be assessed at baseline and Week 12. Calorie intake using the apps will be prompted at Weeks 4, 8, and 12 .

Motivation to participate in a weight management program is one of the key elements of its success [72]. This construct will be assessed using the Treatment Self-Regulation Questionnaire (TSRQ) [72-74]. TSRQ includes autonomous and controlled regulation subscales. Motivation to participate in the program will be assessed at baseline and Weeks 4, 8, and 12 . Additionally, stages and processes of change in weight management will be assessed using the S- and P-Weight scales [75,76]. The S- and P-Weight scales assess the cognitive predictors of weight change [77]. These scales are based on the transtheoretical model and include stages of change (S-Weight) and processes of change (P-Weight) components to assess the motivation to lose weight, which can be considered both a moderator and a mediator or covariate factor in achieving the main outcome (ie, weight loss). Stages and processes of change will be assessed at baseline and Week 12 .

\section{Data Collection and Management}

Except for the 24-hour recall/record done through the Web-based ASA24 platform, process and outcome measurements will be collected through REDCap [44], which is a secure, the Health Insurance Portability and Accountability Act compliant, Web-based survey application hosted on AUB servers. REDCap is an ideal program for managing longitudinal studies with multiple assessments.

\section{Sample Size}

Traditional sample size calculations are not typically undertaken in nonprobability sampling and in pilot interventional studies, as these are intended to test acceptability and evaluate the process as well as to inform power calculations for subsequent studies [78]. Nevertheless, researchers recommend that sample size justifications are provided also in pilot studies [78]. In the absence of similar studies in Lebanon and in the region, it is difficult to estimate precise effect sizes. However, estimates can be derived from the average effect sizes reported in similar mobile-based weight loss interventions that had minimal researcher interaction [79-81], included in Schippers et al's meta-analysis [21]. In these studies, the effect sizes (SMD, standardized mean difference) based on weight change ranged from $d=0.33$ [79] to 0.37 [80]. According to Whitehead et al's tables (for $\mathrm{SMD}=0.3$ and 0.4, respectively) [78], a two-arm trial, designed with $90 \%$ power and two-sided $5 \%$ significance, will require between 305 and 181 participants per arm; a pilot study will require, respectively, 45 and 33 participants per arm [78].

\section{Data Analyses}

Descriptive statistics will be conducted for the overall characteristics of the study population through presenting the numbers and percentages for nominal or categorical variables and means and standard deviations for continuous ones. For variables assessed using multiple items (eg, uMARS scales), Cronbach alpha and corrected item-total correlations coefficients will be used to assess the internal consistency of the measured constructs, before aggregating the information (ie, averaging). Bivariate correlations and chi-square tests will be used to explore associations among demographic and psychographic variables and main study outcomes.

Missing data are expected to be minimal for most variables. Depending on the number of participants, the number of missing data points, and the distribution of the outcome variables, we will decide which missing data strategy to use (eg, full-information maximum likelihood or multiple imputation) [82]. The missing data bias will be assessed by computing a binary variable reflecting the presence or absence of missing data for each variable in the model, and then, this binary variable will be correlated with all other variables in the model as well as an array of demographic variables.

Reliability of the uMARS scales will be evaluated using both indices of interrater agreement (IRA) and interrater reliability (IRR) [83-85]. Following the recommendations from the literature [86,87], IRA will also be measured according to Brown and Hauenstein's aWG index [88], and the adjusted average deviation index ADM (adj) [89]. IRR indices will be based on intraclass correlation coefficients measuring test-retest reliability [90,91]. Similarly, test-retest reliability estimates will be used with the ASA24 Dietary Assessment Tool and the IPAQ-S [57].

Independent samples $t$ tests, one-way analysis of variances (or nonparametric alternatives where appropriate) will be used to test differences in the relevant outcome variables (behavioral, cognitive, and weight-related data) between intervention groups and between pre- and posttest. Behavioral and weight-related data will be presented using appropriate confidence intervals 
as suggested by Lee and colleagues [92]. The estimation of preliminary efficacy will be based on the observed trends on data over time rather than traditional inferential statistics [93]. Subgroup analyses will also include intent-to-treat versus randomized analyses to detect whether differences in the outcomes are associated with adherence to the trial (per protocol).

\section{Results}

Funding for WaznApp study has been secured from the AUB, University Research Board. Recruitment started in February and was completed by the end of March 2018; the study will be completed by the end of June 2018. Data analyses and write-up will start over the summer and be completed by the end of 2018. Any changes in the procedures related to recruitment, eligibility criteria, outcomes, and analyses will be implemented and communicated to study participants via email within 2 weeks from the modifications in the protocol. Results will be communicated in a final report for participants.

\section{Discussion}

This study contributes to the growing evidence on mobile apps for weight management $[18,19]$. The findings of this project will provide information on the feasibility of using commercially available, popular mobile apps as a standalone delivery mode for self-directed interventions for weight management. Furthermore, this study will provide preliminary insights into the potential acceptability and efficacy of an app that acts as a JITAI (Lark) at promoting weight management compared with a non-JITAI, calorie-counting app (MyFitnessPal). Lark has recently been used in an observational study, involving 70 diabetic patients who lost $2.4 \%$ of their weight at baseline after about 15 weeks [48]. MyFitnessPal has been utilized in a few weight loss trials, showing some positive effects in weight reduction when employed as a supplement to telephone coaching [30], but small, no significant effects when used as a standalone tool [31,32]. We hypothesize that the use of Lark will be associated with larger, more positive changes in cognitions, behaviors, and anthropometric measures than the other apps. This hypothesis will be tested in a larger trial. In fact, this feasibility study will be used to inform a subsequent trial with the same target population. The results of the larger study may inform other studies targeting similar workplaces in Lebanon and the MENA region, and may be used as a benchmark for further investigations in other settings and with other target groups.

Anticipated limitations of this study include slow recruitment and participation rates; the use of self-reported data, including app usage and activity; and using Web-based questionnaires that might not capture real-life hurdles and potential reasons for failure. Budgetary limitations did not allow us to include more objective measures of physical activity and dietary behaviors and a comprehensive qualitative evaluation of the trial. Nonetheless, this trial will provide information about low-cost, mobile solutions to help employees self-manage their weight.

\section{Acknowledgments}

This study was funded by the American University of Beirut, University Research Board (Grant \#103369).

\section{Conflicts of Interest}

None declared.

\section{Multimedia Appendix 1}

Peer-reviewer report.

\section{[PDF File (Adobe PDF File), 87KB-Multimedia Appendix 1]}

\section{References}

1. World Health Organization. 2017 Jun. Noncommunicable diseases fact sheet URL: http://www.who.int/mediacentre/ factsheets/fs355/en/ [accessed 2018-04-22] [WebCite Cache ID 6ys6A73ME]

2. World Health Organization. Global status report on noncommunicable diseases 2014. Geneva, Switzerland: World Health Organization; 2014.

3. World Health Organization. 2018 Feb. Obesity and overweight fact sheet URL: http://www.who.int/mediacentre/factsheets/ fs311/en/index.html [accessed 2018-04-22] [WebCite Cache ID 6TIXRI67D]

4. World Health Organization, Ministry of Public Health. Beirut, Lebanon: Ministry of Public Health; 2016 Jan. Non Communicable Diseases Prevention and Control Plan (NCD-PCP) Lebanon 2016-2020 URL: https://www.moph.gov.lb/ en/view/3691/non-communicable-diseases-prevention-and-control-plan-ncd-pcp-lebanon-2016-2020 [accessed 2018-05-04] [WebCite Cache ID 6zB8erzbO]

5. Wilson G. Behavioral treatment of obesity: thirty years and counting. Adv Behav Res Ther 1994 Jan;16(1):31-75. [doi: 10.1016/0146-6402(94)90002-7]

6. Booth HP, Prevost TA, Wright AJ, Gulliford MC. Effectiveness of behavioural weight loss interventions delivered in a primary care setting: a systematic review and meta-analysis. Fam Pract 2014 Dec;31(6):643-653 [FREE Full text] [doi: 10.1093/fampra/cmu064] [Medline: 25298510] 
7. Dombrowski SU, Knittle K, Avenell A, Araújo-Soares V, Sniehotta FF. Long term maintenance of weight loss with non-surgical interventions in obese adults: systematic review and meta-analyses of randomised controlled trials. Br Med J 2014 May 14;348:g2646 [FREE Full text] [Medline: $\underline{25134100}$ ]

8. Finkelstein EA, Kruger E. Meta- and cost-effectiveness analysis of commercial weight loss strategies. Obesity (Silver Spring) 2014 Sep;22(9):1942-1951 [FREE Full text] [doi: 10.1002/oby.20824] [Medline: 24962106]

9. Johns DJ, Hartmann-Boyce J, Jebb SA, Aveyard P, Behavioural Weight Management Review Group. Diet or exercise interventions vs combined behavioral weight management programs: a systematic review and meta-analysis of direct comparisons. J Acad Nutr Diet 2014 Oct;114(10):1557-1568 [FREE Full text] [doi: 10.1016/j.jand.2014.07.005] [Medline: $\underline{25257365]}$

10. Michie S, Richardson M, Johnston M, Abraham C, Francis J, Hardeman W, et al. The behavior change technique taxonomy (v1) of 93 hierarchically clustered techniques: building an international consensus for the reporting of behavior change interventions. Ann Behav Med 2013 Aug;46(1):81-95. [doi: 10.1007/s12160-013-9486-6] [Medline: 23512568]

11. Wing RR, Hill JO. Successful weight loss maintenance. Annu Rev Nutr 2001;21:323-341. [doi: 10.1146/annurev.nutr.21.1.323] [Medline: 11375440 ]

12. Qi BB, Dennis KE. The adoption of eating behaviors conducive to weight loss. Eat Behav 2000 Sep;1(1):23-31. [Medline: 15001064]

13. Mossavar-Rahmani Y, Henry H, Rodabough R, Bragg C, Brewer A, Freed T, et al. Additional self-monitoring tools in the dietary modification component of The Women's Health Initiative. J Am Diet Assoc 2004 Jan;104(1):76-85. [doi: 10.1016/j.jada.2003.10.017] [Medline: 14702588]

14. Eysenbach G. What is e-health? J Med Internet Res 2001;3(2):E20 [FREE Full text] [doi: 10.2196/jmir.3.2.e20] [Medline: 11720962]

15. Chauvin J, Lomazzi M. The digital technology revolution and its impact on the public's health. Eur J Public Health 2017 Dec 01;27(6):947. [doi: 10.1093/eurpub/ckx134] [Medline: 29088447]

16. O'Connor Y, Heavin C. Defining and Characterising the Landscape of eHealth. In: Khosrow-Pour M, editor. Encyclopedia of Information Science and Technology, Fourth Edition. Hershey, PA, USA: IGI Global; 2018:5864.

17. Shaw T, McGregor D, Brunner M, Keep M, Janssen A, Barnet S. What is eHealth (6)? Development of a conceptual model for eHealth: qualitative study with key informants. J Med Internet Res 2017 Oct 24;19(10):e324 [FREE Full text] [doi: 10.2196/jmir.8106] [Medline: 29066429]

18. Bardus M, Smith JR, Samaha L, Abraham C. Mobile and Web 2.0 interventions for weight management: an overview of review evidence and its methodological quality. Eur J Public Health 2016 Dec;26(4):602-610 [FREE Full text] [doi: 10.1093/eurpub/ckw090] [Medline: 27335330]

19. Bardus M, Smith JR, Samaha L, Abraham C. Mobile phone and web 2.0 technologies for weight management: a systematic scoping review. J Med Internet Res 2015 Nov 16;17(11):e259 [FREE Full text] [doi: 10.2196/jmir.5129] [Medline: 26573984]

20. Flores MG, Granado-Font E, Ferré-Grau C, Montaña-Carreras X. Mobile phone apps to promote weight loss and increase physical activity: a systematic review and meta-analysis. J Med Internet Res 2015 Nov 10;17(11):e253 [FREE Full text] [doi: 10.2196/jmir.4836] [Medline: 26554314]

21. Schippers M, Adam PC, Smolenski DJ, Wong HT, de Wit JB. A meta-analysis of overall effects of weight loss interventions delivered via mobile phones and effect size differences according to delivery mode, personal contact, and intervention intensity and duration. Obes Rev 2017 Apr;18(4):450-459. [doi: 10.1111/obr.12492] [Medline: 28187246]

22. Semper HM, Povey R, Clark-Carter D. A systematic review of the effectiveness of smartphone applications that encourage dietary self-regulatory strategies for weight loss in overweight and obese adults. Obes Rev 2016 Dec;17(9):895-906. [doi: 10.1111/obr.12428] [Medline: 27192162]

23. Kozak AT, Buscemi J, Hawkins MA, Wang ML, Breland JY, Ross KM, et al. Technology-based interventions for weight management: current randomized controlled trial evidence and future directions. J Behav Med 2017 Feb;40(1):99-111. [doi: 10.1007/s10865-016-9805-z] [Medline: 27783259]

24. Stephani V, Opoku D, Quentin W. A systematic review of randomized controlled trials of mHealth interventions against non-communicable diseases in developing countries. BMC Public Health 2016 Dec 15;16:572 [FREE Full text] [doi: 10.1186/s12889-016-3226-3] [Medline: 27417513]

25. Müller AM, Alley S, Schoeppe S, Vandelanotte C. The effectiveness of e-\& mHealth interventions to promote physical activity and healthy diets in developing countries: a systematic review. Int J Behav Nutr Phys Act 2016 Dec 10;13(1):109 [FREE Full text] [doi: 10.1186/s12966-016-0434-2] [Medline: 27724911]

26. Pew Research Center. Pew Global. 2014 Feb 13. Emerging Nations Embrace Internet, Mobile Technology Internet URL: http://www.pewglobal.org/2014/02/13/emerging-nations-embrace-internet-mobile-technology/ [accessed 2018-04-22] [WebCite Cache ID 6vZxvRh2t]

27. Klasnja P, Pratt W. Healthcare in the pocket: mapping the space of mobile-phone health interventions. J Biomed Inform 2012 Feb;45(1):184-198 [FREE Full text] [doi: 10.1016/j.jbi.2011.08.017] [Medline: 21925288]

28. Tang J, Abraham C, Greaves C, Yates T. Self-directed interventions to promote weight loss: a systematic review of reviews. J Med Internet Res 2014 Feb 19;16(2):e58 [FREE Full text] [doi: 10.2196/jmir.2857] [Medline: 24554464] 
29. Chen J, Lieffers J, Bauman A, Hanning R, Allman-Farinelli M. The use of smartphone health apps and other mobile health (mHealth) technologies in dietetic practice: a three country study. J Hum Nutr Diet 2017 Aug;30(4):439-452. [doi: 10.1111/jhn.12446] [Medline: 28116773 ]

30. Hartman SJ, Nelson SH, Cadmus-Bertram LA, Patterson RE, Parker BA, Pierce JP. Technology- and phone-based weight loss intervention: pilot RCT in women at elevated breast cancer risk. Am J Prev Med 2016 Nov;51(5):714-721 [FREE Full text] [doi: 10.1016/j.amepre.2016.06.024] [Medline: 27593420]

31. Laing BY, Mangione CM, Tseng C, Leng M, Vaisberg E, Mahida M, et al. Effectiveness of a smartphone application for weight loss compared with usual care in overweight primary care patients: a randomized, controlled trial. Ann Intern Med 2014 Nov 18;161(10 Suppl):S5-12 [FREE Full text] [doi: 10.7326/M13-3005] [Medline: 25402403]

32. Jospe MR, Roy M, Brown RC, Williams SM, Osborne HR, Meredith-Jones KA, et al. The effect of different types of monitoring strategies on weight loss: a randomized controlled trial. Obesity (Silver Spring) 2017 Sep;25(9):1490-1498. [doi: 10.1002/oby.21898] [Medline: 28703448]

33. Nahum-Shani I, Smith SN, Spring BJ, Collins LM, Witkiewitz K, Tewari A, et al. Just-in-Time Adaptive Interventions (JITAIs) in mobile health: key components and design principles for ongoing health behavior support. Ann Behav Med 2016 Sep 23 Epub ahead of print(forthcoming) [FREE Full text] [doi: 10.1007/s12160-016-9830-8] [Medline: 27663578]

34. Nahum-Shani I, Hekler E, Spruijt-Metz D. Building health behavior models to guide the development of just-in-time adaptive interventions: a pragmatic framework. Health Psychol 2015 Dec;34S:1209-1219 [FREE Full text] [doi: 10.1037/hea0000306] [Medline: 26651462]

35. World Health Organization. Global action plan for the prevention and control of noncommunicable diseases $2013-2020$. Geneva, Switzerland: World Health Organization; 2013:103.

36. International Labour Organization. 2011 Oct. ILO estimates and projections of the economically active population 1990-2020 (sixth edition) URL: http://laborsta.ilo.org/applv8/data/EAPEP/v6/ILO_EAPEP_methodology_2011.pdf [accessed 2018-05-04] [WebCite Cache ID 6zB9PPWuq]

37. Anderson LM, Quinn TA, Glanz K, Ramirez G, Kahwati LC, Johnson DB, Task Force on Community Preventive Services. The effectiveness of worksite nutrition and physical activity interventions for controlling employee overweight and obesity: a systematic review. Am J Prev Med 2009 Oct;37(4):340-357. [doi: 10.1016/j.amepre.2009.07.003] [Medline: 19765507]

38. Bélanger-Gravel A, Godin G, Vézina-Im LA, Amireault S, Poirier P. The effect of theory-based interventions on physical activity participation among overweight/obese individuals: a systematic review. Obes Rev 2011 Jun;12(6):430-439. [doi: 10.1111/j.1467-789X.2010.00729.x] [Medline: 20331511]

39. Craigie AM, Lake AA, Kelly SA, Adamson AJ, Mathers JC. Tracking of obesity-related behaviours from childhood to adulthood: a systematic review. Maturitas 2011 Nov;70(3):266-284. [doi: 10.1016/j.maturitas.2011.08.005] [Medline: 21920682]

40. Enwald HP, Huotari MA. Preventing the obesity epidemic by second generation tailored health communication: an interdisciplinary review. J Med Internet Res 2010 Jun 28;12(2):e24 [FREE Full text] [doi: 10.2196/jmir.1409] [Medline: 20584698]

41. American University of Beirut. 2017. American University of Beirut Facts and Figures 2017 URL: https://website.aub.edu.lb/ main/about/Documents/facts-figures-17.pdf [accessed 2018-04-22] [WebCite Cache ID 6ysDV1z4W]

42. Altman DG, Bland JM. Treatment allocation by minimisation. Br Med J 2005 Apr 09;330(7495):843 [FREE Full text] [doi: 10.1136/bmj.330.7495.843] [Medline: 15817555$]$

43. O'Callaghan CA. OxMaR: open source free software for online minimization and randomization for clinical trials. PLoS One 2014;9(10):e110761 [FREE Full text] [doi: 10.1371/journal.pone.0110761] [Medline: 25353169]

44. Harris PA, Taylor R, Thielke R, Payne J, Gonzalez N, Conde JG. Research electronic data capture (REDCap)--a metadata-driven methodology and workflow process for providing translational research informatics support. J Biomed Inform 2009 Apr;42(2):377-381 [FREE Full text] [doi: 10.1016/j.jbi.2008.08.010] [Medline: 18929686]

45. Stoyanov SR, Hides L, Kavanagh DJ, Zelenko O, Tjondronegoro D, Mani M. Mobile app rating scale: a new tool for assessing the quality of health mobile apps. JMIR Mhealth Uhealth 2015 Mar 11;3(1):e27 [FREE Full text] [doi: 10.2196/mhealth.3422] [Medline: 25760773]

46. Bardus M, Van Beurden S, Smith JR, Abraham C. A review and content analysis of engagement, functionality, aesthetics, information quality, and change techniques in the most popular commercial apps for weight management. Int J Behav Nutr Phys Act 2016 Mar 10;13:35 [FREE Full text] [doi: 10.1186/s12966-016-0359-9] [Medline: 26964880]

47. Stoyanov SR, Hides L, Kavanagh DJ, Wilson H. Development and validation of the user version of the Mobile Application Rating Scale (uMARS). JMIR Mhealth Uhealth 2016 Jun 10;4(2):e72 [FREE Full text] [doi: 10.2196/mhealth.5849] [Medline: 27287964]

48. Stein N, Brooks K. A fully automated conversational artificial intelligence for weight loss: longitudinal observational study among overweight and obese adults. JMIR Diabetes 2017 Nov 01;2(2):e28. [doi: 10.2196/diabetes.8590]

49. Chen J, Lieffers J, Bauman A, Hanning R, Allman-Farinelli M. The use of smartphone health apps and other mobile health (mHealth) technologies in dietetic practice: a three country study. J Hum Nutr Diet 2017 Aug;30(4):439-452. [doi:

10.1111/jhn.12446] [Medline: 28116773] 
50. Skwarecki B. Lifehacker. 2017 Feb 26. Diet Tracker Showdown: MyFitnessPal vs Lose It URL: https://lifehacker.com/ diet-tracker-showdown-myfitnesspal-vs-lose-it-1792754350 [accessed 2018-04-22] [WebCite Cache ID 6ysEA69Sk]

51. Lin P, Intille S, Bennett G, Bosworth HB, Corsino L, Voils C, et al. Adaptive intervention design in mobile health: intervention design and development in the Cell Phone Intervention for You trial. Clin Trials 2015 Dec;12(6):634-645 [FREE Full text] [doi: 10.1177/1740774515597222] [Medline: 26229119]

52. Svetkey LP, Batch BC, Lin P, Intille SS, Corsino L, Tyson CC, et al. Cell phone intervention for you (CITY): a randomized, controlled trial of behavioral weight loss intervention for young adults using mobile technology. Obesity (Silver Spring) 2015 Nov;23(11):2133-2141 [FREE Full text] [doi: 10.1002/oby.21226] [Medline: 26530929]

53. Solbrig L, Jones R, Kavanagh D, May J, Parkin T, Andrade J. People trying to lose weight dislike calorie counting apps and want motivational support to help them achieve their goals. Internet Interv 2017 Mar; 7:23-31 [FREE Full text] [doi: 10.1016/j.invent.2016.12.003] [Medline: 28286739]

54. Pellett PL, Shadarevian S. Food composition tables for use in the Middle East (3rd edition). Beirut, Lebanon: American University of Beirut; 2013:103.

55. Zichermann G, Cunningham C. Gamification by Design: Implementing Game Mechanics in Web and Mobile Apps. Sebastopol, CA, USA: O'Reilly Media, Inc; 2011.

56. Ni MC, Whittaker R, McRobbie H, Ball K, Crawford D, Michie J, et al. Feasibility, acceptability and potential effectiveness of a mobile health (mHealth) weight management programme for New Zealand adults. BMC Obes 2014;1:10 [FREE Full text] [doi: 10.1186/2052-9538-1-10] [Medline: 26217502]

57. IPAQ Research Committee. 2011. Background - International Physical Activity Questionnaire URL: https://sites.google.com/ site/theipaq/background [accessed 2018-04-22] [WebCite Cache ID 6wOi78iYU]

58. Sylvia LG, Bernstein EE, Hubbard JL, Keating L, Anderson EJ. Practical guide to measuring physical activity. J Acad Nutr Diet 2014 Feb;114(2):199-208 [FREE Full text] [doi: 10.1016/j.jand.2013.09.018] [Medline: 24290836]

59. Craig CL, Marshall AL, Sjöström M, Bauman AE, Booth ML, Ainsworth BE, et al. International physical activity questionnaire: 12-country reliability and validity. Med Sci Sports Exerc 2003 Aug;35(8):1381-1395. [doi: 10.1249/01.MSS.0000078924.61453.FB] [Medline: 12900694]

60. Chamieh MC, Moore HJ, Summerbell C, Tamim H, Sibai AM, Hwalla N. Diet, physical activity and socio-economic disparities of obesity in Lebanese adults: findings from a national study. BMC Public Health 2015 Mar 21;15:279 [FREE Full text] [doi: 10.1186/s12889-015-1605-9] [Medline: 25880751]

61. Sibai AM, Costanian C, Tohme R, Assaad S, Hwalla N. Physical activity in adults with and without diabetes: from the 'high-risk' approach to the 'population-based' approach of prevention. BMC Public Health 2013 Oct 24;13:1002 [FREE Full text] [doi: 10.1186/1471-2458-13-1002] [Medline: 24153099]

62. IPAQ Research Committee. 2005 Nov. Guidelines for Data Processing and Analysis of the International Physical Activity Questionnaire (IPAQ) - Short and Long Forms URL: https://sites.google.com/site/theipaq/scoring-protocol [accessed 2018-04-22] [WebCite Cache ID 6ysF2XFQB]

63. Ainsworth BE, Haskell WL, Herrmann SD, Meckes N, Bassett DR, Tudor-Locke C, et al. 2011 Compendium of Physical Activities: a second update of codes and MET values. Med Sci Sports Exerc 2011 Aug;43(8):1575-1581. [doi: 10.1249/MSS.0b013e31821ece12] [Medline: 21681120]

64. Moshfegh AJ, Rhodes DG, Baer DJ, Murayi T, Clemens JC, Rumpler WV, et al. The US Department of Agriculture Automated Multiple-Pass Method reduces bias in the collection of energy intakes. Am J Clin Nutr 2008 Aug;88(2):324-332. [doi: 10.1093/ajcn/88.2.324] [Medline: 18689367]

65. Kirkpatrick SI, Potischman N, Dodd KW, Douglass D, Zimmerman TP, Kahle LL, et al. The use of digital images in 24-hour recalls may lead to less misestimation of portion size compared with traditional interviewer-administered recalls. J Nutr 2016 Dec;146(12):2567-2573 [FREE Full text] [doi: 10.3945/jn.116.237271] [Medline: 27807039]

66. Turner-McGrievy GM, Beets MW, Moore JB, Kaczynski AT, Barr-Anderson DJ, Tate DF. Comparison of traditional versus mobile app self-monitoring of physical activity and dietary intake among overweight adults participating in an mHealth weight loss program. J Am Med Inform Assoc 2013 May 01;20(3):513-518 [FREE Full text] [doi: 10.1136/amiajnl-2012-001510] [Medline: 23429637]

67. Turner-McGrievy G, Tate D. Tweets, Apps, and Pods: Results of the 6-month Mobile Pounds Off Digitally (Mobile POD) randomized weight-loss intervention among adults. J Med Internet Res 2011 Dec 20;13(4):e120 [FREE Full text] [doi: 10.2196/jmir.1841] [Medline: 22186428]

68. Steinberg DM, Tate DF, Bennett GG, Ennett S, Samuel-Hodge C, Ward DS. The efficacy of a daily self-weighing weight loss intervention using smart scales and e-mail. Obesity (Silver Spring) 2013 Sep;21(9):1789-1797 [FREE Full text] [doi: 10.1002/oby.20396] [Medline: 23512320]

69. Thompson FE, Dixit-Joshi S, Potischman N, Dodd KW, Kirkpatrick SI, Kushi LH, et al. Comparison of interviewer-administered and automated self-administered 24-hour dietary recalls in 3 diverse integrated health systems. Am J Epidemiol 2015 Jun 15;181(12):970-978 [FREE Full text] [doi: 10.1093/aje/kwu467] [Medline: 25964261]

70. Kirkpatrick SI, Subar AF, Douglass D, Zimmerman TP, Thompson FE, Kahle LL, et al. Performance of the automated self-administered 24-hour recall relative to a measure of true intakes and to an interviewer-administered 24-h recall. Am J Clin Nutr 2014 Jul;100(1):233-240 [FREE Full text] [doi: 10.3945/ajcn.114.083238] [Medline: 24787491] 
71. Kirkpatrick SI, Gilsing AM, Hobin E, Solbak NM, Wallace A, Haines J, et al. Lessons from studies to evaluate an online 24-hour recall for use with children and adults in Canada. Nutrients 2017 Jan 31;9(2) [FREE Full text] [doi: 10.3390/nu9020100] [Medline: 28146125]

72. Williams GC, Grow VM, Freedman ZR, Ryan RM, Deci EL. Motivational predictors of weight loss and weight-loss maintenance. J Pers Soc Psychol 1996 Jan;70(1):115-126. [Medline: 8558405]

73. Levesque CS, Williams GC, Elliot D, Pickering MA, Bodenhamer B, Finley PJ. Validating the theoretical structure of the Treatment Self-Regulation Questionnaire (TSRQ) across three different health behaviors. Health Educ Res 2007 Oct;22(5):691-702. [doi: 10.1093/her/cyl148] [Medline: 17138613]

74. Webber KH, Gabriele JM, Tate DF, Dignan MB. The effect of a motivational intervention on weight loss is moderated by level of baseline controlled motivation. Int J Behav Nutr Phys Act 2010 Jan 22;7:4 [FREE Full text] [doi: 10.1186/1479-5868-7-4] [Medline: 20157441]

75. Andrés A, Saldaña C, Gómez-Benito J. Establishing the stages and processes of change for weight loss by consensus of experts. Obesity (Silver Spring) 2009 Sep;17(9):1717-1723 [FREE Full text] [doi: 10.1038/oby.2009.100] [Medline: 19360014]

76. Andrés A, Saldaña C, Gómez-Benito J. The transtheoretical model in weight management: validation of the processes of change questionnaire. Obes Facts 2011;4(6):433-442 [FREE Full text] [doi: 10.1159/000335135] [Medline: 22248993]

77. Ceccarini M, Borrello M, Pietrabissa G, Manzoni GM, Castelnuovo G. Assessing motivation and readiness to change for weight management and control: an in-depth evaluation of three sets of instruments. Front Psychol 2015;6:511 [FREE Full text] [doi: 10.3389/fpsyg.2015.00511] [Medline: 26029126]

78. Whitehead AL, Julious SA, Cooper CL, Campbell MJ. Estimating the sample size for a pilot randomised trial to minimise the overall trial sample size for the external pilot and main trial for a continuous outcome variable. Stat Methods Med Res 2016 Dec;25(3):1057-1073 [FREE Full text] [doi: 10.1177/0962280215588241] [Medline: 26092476]

79. Carter MC, Burley VJ, Cade JE. Development of 'My Meal Mate' - a smartphone intervention for weight loss. Nutrition Bulletin 2013 Feb 07;38(1):80-84. [doi: 10.1111/nbu.12016]

80. Glynn LG, Hayes PS, Casey M, Glynn F, Alvarez-Iglesias A, Newell J, et al. Effectiveness of a smartphone application to promote physical activity in primary care: the SMART MOVE randomised controlled trial. Br J Gen Pract 2014 Jul;64(624):e384-e391 [FREE Full text] [doi: 10.3399/bjgp14X680461] [Medline: 24982490]

81. Prestwich A, Perugini M, Hurling R. Can implementation intentions and text messages promote brisk walking? A randomized trial. Health Psychol 2010 Jan;29(1):40-49. [doi: 10.1037/a0016993] [Medline: 20063934]

82. Graham JW. Missing data analysis: making it work in the real world. Annu Rev Psychol 2009;60:549-576. [doi: 10.1146/annurev.psych.58.110405.085530] [Medline: 18652544]

83. Gwet K. Handbook of Inter-Rater Reliability: The Definitive Guide to Measuring the Extent of Agreement Among Multiple Raters, 3rd Edition. 3rd edition. Gaithersburg, MD, USA: Advanced Analytics, LLC; 2012.

84. Hallgren KA. Computing inter-rater reliability for observational data: an overview and tutorial. Tutor Quant Methods Psychol 2012;8(1):23-34 [FREE Full text] [Medline: 22833776]

85. Gisev N, Bell JS, Chen TF. Interrater agreement and interrater reliability: key concepts, approaches, and applications. Res Social Adm Pharm 2013;9(3):330-338. [doi: 10.1016/j.sapharm.2012.04.004] [Medline: 22695215]

86. O'Neill TA. An overview of interrater agreement on Likert scales for researchers and practitioners. Front Psychol 2017;8:777 [FREE Full text] [doi: 10.3389/fpsyg.2017.00777] [Medline: 28553257]

87. LeBreton JM, Senter JL. Answers to 20 questions about interrater reliability and interrater agreement. Organ Res Methods 2007 Nov 28;11(4):815-852. [doi: $10.1177 / 1094428106296642$ ]

88. Brown RD, Hauenstein NM. Interrater agreement reconsidered: an alternative to the rwg indices. Organ Res Methods 2016 Jun 29;8(2):165-184. [doi: 10.1177/1094428105275376]

89. Lohse-Bossenz H, Kunina-Habenicht O, Kunter M. Estimating within-group agreement in small groups: a proposed adjustment for the average deviation index. Eur J Work Organ Psychol 2013 Jan 25;23(3):456-468. [doi: 10.1080/1359432X.2012.748189]

90. Weir JP. Quantifying test-retest reliability using the intraclass correlation coefficient and the SEM. J Strength Cond Res 2005 Feb;19(1):231-240. [doi: 10.1519/15184.1] [Medline: 15705040]

91. Yen M, Lo L. Examining test-retest reliability: an intra-class correlation approach. Nurs Res 2002;51(1):59-62. [Medline: $\underline{11822570]}$

92. Lee EC, Whitehead AL, Jacques RM, Julious SA. The statistical interpretation of pilot trials: should significance thresholds be reconsidered? BMC Med Res Methodol 2014 Mar 20;14:41 [FREE Full text] [doi: 10.1186/1471-2288-14-41] [Medline: 24650044]

93. Leon AC, Davis LL, Kraemer HC. The role and interpretation of pilot studies in clinical research. J Psychiatr Res 2011 May;45(5):626-629 [FREE Full text] [doi: 10.1016/j.jpsychires.2010.10.008] [Medline: 21035130]

\section{Abbreviations}

ASA24: Automated Self-Administered 24-hour 
AUB: American University of Beirut

AUBMC: American University of Beirut Medical Center

IPAQ-S: International Physical Activity Questionnaire, short form

IRA: interrater agreement

IRR: interrater reliability

JITAI: Just-in-Time Adaptive Interventions

MARS: Mobile App Rating Scale

MET: metabolic equivalent

MENA: Middle East and North Africa

mHealth: mobile health

NCD: noncommunicable disease

TSRQ: Treatment Self-Regulation Questionnaire

UHS: University Health Services

uMARS: user version of the MARS Scale

WAKpt(s): WaznApp Karma Point(s)

WHO: World Health Organization

Edited by G Eysenbach; submitted 07.01.18; peer-reviewed by A Müller, B Kim, A Sharafoddini; comments to author 22.02.18; revised version received 18.03.18; accepted 31.03.18; published 16.05.18

Please cite as:

Bardus $M$, Hamadeh $G$, Hayek $B$, Al Kherfan $R$

A Self-Directed Mobile Intervention (WaznApp) to Promote Weight Control Among Employees at a Lebanese University: Protocol for a Feasibility Pilot Randomized Controlled Trial

JMIR Res Protoc 2018;7(5):e133

URL: http://www.researchprotocols.org/2018/5/e133/

doi: $10.2196 /$ resprot. 9793

PMID: 29769174

(CMarco Bardus, Ghassan Hamadeh, Bouchra Hayek, Rawan Al Kherfan. Originally published in JMIR Research Protocols (http://www.researchprotocols.org), 16.05.2018. This is an open-access article distributed under the terms of the Creative Commons Attribution License (https://creativecommons.org/licenses/by/4.0/), which permits unrestricted use, distribution, and reproduction in any medium, provided the original work, first published in JMIR Research Protocols, is properly cited. The complete bibliographic information, a link to the original publication on http://www.researchprotocols.org, as well as this copyright and license information must be included. 